\title{
Rhinosinugenic Intracranial Abscesses: A Review Of 4 Cases From Ile-Ife, Nigeria
}

\author{
A Adeniji, Y Amusa, O Akinpelu, A Adeolu, E Komolafe, O Onipede
}

\begin{abstract}
Citation
A Adeniji, Y Amusa, O Akinpelu, A Adeolu, E Komolafe, O Onipede. Rhinosinugenic Intracranial Abscesses: A Review Of 4 Cases From Ile-Ife, Nigeria. The Internet Journal of Otorhinolaryngology. 2008 Volume 9 Number 1.
\end{abstract}

DOI: $\underline{10.5580 / \mathrm{d} 78}$

\begin{abstract}
Background and Objective: Intracranial abscesses complicating rhinosinusitis are now uncommon. Attitude of patients to the so called common cold, delay in diagnosis and relative inaccessibility to computed tomography scan contribute to persistence of the entity and its sequelae in our environment.

Case Description: Four patients presented to our centre with this condition over an eighteen month period. All were male teenagers. Late presentation was common to all, and rhinological symptoms were less emphasized. Radical treatment of the intracranial abscesses and three of the primary foci was employed. Three of the patients were left with morbidities while one died.

Conclusion: Claims of its rarity may not continue to be true in the developing countries where the factors associated with poverty and low socioeconomic standard of living are prevalent. Therefore clinicians need to be more alert and work as a team for early diagnosis and reduce its morbidity and mortality. Parents need to be educated.
\end{abstract}

\section{INTRODUCTION}

Rhinosinugenic intracranial abscesses have been uncommon since the introduction of antibiotics, and with the use of radical surgery and the introduction of CT scan there has been a decrease in incidence of morbidity and mortality ${ }_{1,2,3}$. This clinical entity is of great importance since it represents a severe disease with life threatening consequences ${ }_{1,2,5}$. Intracranial complications occur in $0.01-3.3 \%$ of patients with Rhinosinusitis ${ }_{2,4}$. Out of these, less percentage are frank abscesses.

The most common predisposing factor for intracranial complications is altered sinus physiology due to chronic sinusitis. When this is superimposed with bouts of acute infection which are treated with inappropriate or inadequate dosage of antibiotics, they mask the symptoms associated with intracranial complications and therefore delay the diagnosis and treatment and increase the severity of complications ${ }_{5}$. Other predisposing factors include structural abnormalities like bony dehiscence in the skull base, tumours, immunologic incompetence or diabetes ${ }_{6}$.

Frontal sinus is the most often involved, followed by the ethmoid, sphenoid and the maxillary. All the paranasal sinuses, except the maxillary, have a wall in common with the cranial cavity which is often a very thin bone ${ }_{6}$.

Intracranial suppuration may be a complication of paranasal sinus disease by the following mechanisms: Penetrating trauma, direct extension along tissue planes, haematogenous or metastatic spread from sinus or paranasal infection, lymphatic spread and spread through the perineural spaces have been reported ${ }_{8,9}$.

The most common mechanism of intracranial spread of sinus infection is via thrombophlebitis of valveless veins. Mosher and Judd, in 1933 described a complex system of valveless diploic veins (of Breschet) that allowed bacteria to travel via thrombophlebitic process from the sinus mucosa, through the frontal bone to dura vessels or into the superior sagittal sinus or the cavernous sinus ${ }_{10}$. Extension into the subarachnoid space or brain may also occur in this fashion ${ }_{11}, 12$

The cases presented illustrate the effect of delayed diagnosis and commencement of treatment, as well as ineffective antibiotic treatment of paranasal sinus infection likely due to 
the underestimation of the possible havoc that may be done; and the importance of radiologic investigation especially contrast enhanced CT scan and MRI. The presentation of this crop of patients within an eighteen-month period, however, raises a question about the compliance of the physician with various suggestions on the approach to this patients-especially the high index of suspicion; also, the possibility of increasing virulence of the organisms and antibiotic abuse leading to resistance, and the degree of utilization of the high technology radiological investigations. Hence, the need to take urgent steps to forestall further occurrences of this preventable condition.

\section{CASE I}

O.O was a 14 year old male patient who presented at the children emergency unit with fever and right eye swelling of three weeks, headache, convulsion and right sided scalp swelling of a week duration. CT scan of the brain and the paranasal sinuses revealed right frontal soft tissue swelling, massive right frontoparietal subdural collection with a gross midline shift and effacement of the ipsilateral right lateral ventricle. In addition, there was collection within the right frontal, ethmoidal, sphenoidal and the maxillary sinuses (fig 1). Patient had emergency surgery to drain the right subgaleal abscess, right frontoparietal burr holes to drain the subdural empyema. Right ethmoidosphenoidotomy with antral lavage. Patient was admitted into intensive care unit (ICU) postoperatively, and was placed on intravenous (IV) antibiotics according to sensitivity for two weeks. He made a remarkable clinical improvement, but had a residual left hemiparesis and speech deficit. He was discharged on the 21 st day of admission for physiotherapy and speech therapy. He has made remarkable improvement, however irregular clinic attendance is militating against rehabilitation.

\section{Figure 1}

Figure 1

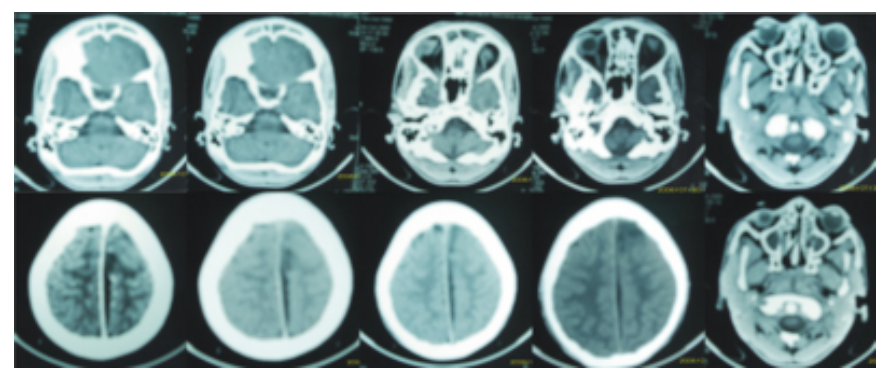

\section{CASE 2}

F.O was a 16-year old male patient admitted via the Accident and Emergency unit of our hospital. He presented with fever, headache, excessive day time somnolence, left periorbital swelling, aphasia, and right hemiparesis. He had an emergency exploratory burrhole for drainage of the left frontal and parietal epidural and subdural abscesses and left antral lavage based on X-rays. Patients clinical condition however deteriorated and then had a contrast enhanced CT scan which revealed a frontal subdural, interhemispheric collections with a left maxillary and ethmoidal collection. Following this, patient had frontal craniotomy for the evacuation of the subdural abscesses with a repeat antral lavage. He was placed on intravenous Ofloxacin and metronidazole based on sensitivity. He also had ICU admission and other supportive management. He had significant clinical improvement but had a residual right hemiparesis and speech defect and was discharged for physiotherapy and speech therapy on the $23{ }^{\text {rd }}$ day of admission. I saw him months later with marked improvement in terms of weight gain,improved speech and paresis.

\section{CASE 3}

A.S was a 14-year old male patient who presented via the Children emergency ward of our centre with fever, headache, vomiting, left periorbital swelling, bilateral purulent rhinorhoea, excessive daytime somnolence and right hemiparesis. Patient later developed aphasia while on admission. Essential findings on examination were an acutely ill looking young boy, febrile, 39.5 degrees centigrade, mucopurulent rhinorhoea, hyperaemic oropharynx with granular posterior pharyngeal wall. Patient had associated left parotid abscess, with left upper molar periapical abscess, left proptosis, chemosis. His visual acuity was counting finger grossly in both eyes. CT findings included a left frontal subdural collection with brilliant rim enhancement, interhemispheric collections, left frontal, ethmoidal and maxillary sinuses collection Fig 2. Patient had frontal craniotomy for evacuation of the intracranial abscesses, Left frontoethmoidectomy with frontal sinus exenteration and repeated bilateral antral lavage. Patient had craniotomy thrice on account of reaccumulation of pus in the intracranial cavity. The parotid, the periapical and the periorbital abscesses were also drained. Patient was placed on IV Ceftriaxone, Cefuroxime, Ceftazidime, Ofloxacin and Metronidazole at different times based on sensitivity and the microbiologist review although patient had poor drug compliance due to financial constraints. Microbiologist review was necessitated due to the failure of resolution of the abscess despite repeated surgical drainage and antibiotic use; they were also needed due to the failure of compliance 
to prescription on the part of the patient relative. He also had ICU admission for the initial period with other supportive treatment including blood transfusion of eight pints. Patient's clinical condition was however fluctuating with periods of clinical progress and regression with these periods corresponding to the period of compliance and noncompliance with drug. Patient died after 6 weeks on admission.

\section{Figure 2}

Figure 2

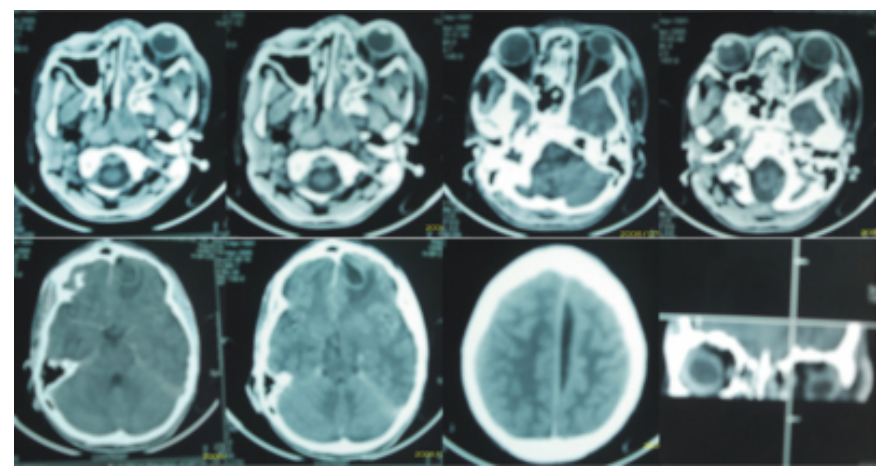

\section{CASE 4}

A.O was a 15 -year old male patient who presented to the accident and emergency unit of our hospital with fever, headache, excessive daytime somnolence seizure, right hemiparesis and aphasia. Patient had a background history of recurrent nasal discharge 4years for which he has been on treatment with antibiotics by a primary physician. Essential findings on examination are a young boy that was acutely ill looking, febrile 39.5 degree centigrade, facial swelling, and aphasic with right hemiparesis. CT findings revealed Left parasagittal hypodense collection, with collection within the frontal, maxillary and ethmoidal sinuses .Patient was commenced on parenteral Cefuroxime, Metronidazole and other supportive treatment. Patient had frontal craniotomy for the evacuation of pus, left frontoethmoidectomy with bilateral antral lavage out. Following treatment patient had a good postoperative recovery. He however had residual speech defect and right hemiparesis. He was discharged after five and a half weeks on admission for speech rehabilitation and physiotherapy. Patient has been followed up for 24 months in the clinic with sustained improvement.

\section{DISCUSSION}

Intracranial abscesses are serious medical condition and present considerable threat to life and appreciable morbidity to its survivors ${ }_{13}$

Claims that intracranial complications are rare in this antibiotic era have been made by a number of researchers ${ }_{14}, 15$ including Devgan, Devgan and cross(1978); Sable, Hengeren and Powell (1984) Balm et al (1985) even claimed that osteomyelitis of the frontal bone is so rare that it has become a medical curiosity. This has however not been found to be consistently so in our own environment where there is ignorance, widespread misuse and self treatment with various drugs, and the rate of hospital attendance is low probably due to lack of funds and unavailability of an health insurance scheme. Also neuroimaging facilities for radiodiagnosis, where available (in the tertiary hospitals) are epileptic in function due to lack adequate maintenance and technical know-how, and are still relatively unaffordable.

The age range of these patients were between fourteen and sixteen years, all were teenagers and were males. This in agreement with previous reports; Small $\mathrm{M}_{3}$, S Chalstrey, AG etal. ${ }_{18}$ showed that rhinosinugenic intracranial abscesses occurred predominantly in young age group who are possibly predisposed to the intracranial spread of infection by the presence of a developmental dehiscence in the ethmoid, posterior bone wall of the frontal sinus but is at variance with Amadasun from the southern part of Nigeria in which most of the patient were within the third to the fifth decades of life.

In all the patients a history of chronic rhinosinusitis was downplayed by the parents although it was well established that all had a longstanding history of chronic rhinosinusitis which is either being treated by self medication or by the primary physician and none of the patients had a previous sinus radiograph. It has been repeatedly stressed in the past that identification and early treatment of the primary focus as well as early recognition and diagnosis of the intracranial spread of infection (based on a high index of clinical suspicion in 'at risk' patient) are two of the most important factors which must be addressed if the management of intracranial abscesses must improve ${ }_{18}$.

ENT diseases continues to represent the major source of intracranial abscess incidence ranging between 58\% ${ }_{13}$ and $69 \%{ }_{17}$ of cases, sinusitis is the most common cause of subdural empyema. Schiller et al (1948); Wood (1952); Bannister et al (1981) and Sable et al (1984) all reported over $70 \%$ sinugenic causes in their series of subdural empyema while Amadasun et al (1997) ${ }_{19}$ from Nigeria reported $83 \%$. This series demonstrates in accordance with others that surprisingly few such cases present initially to the ENT surgeon and may explain the frequent failure to suspect 
the underlying ENT condition and recognize the early development of intracranial abscess. Efforts should therefore be made for a collaborative work between ENT surgeons Neurosurgeons and other specialists working in the head and neck region.

Early features which suggest intracranial spread of infection resulting from dural irritation and localized encephatitis have been previously ${ }_{13}$ described and include restlessness, neck stiffness, vomiting, headache of which the later is by far the most common. Physicians should look out for these.

Intracranial abscess from an acute frontal sinusitis presents a difficult problem. The main symptom of frontal headache is common to a multitude of other conditions which frequently precipitates referral to a wide variety of non surgical specialities $_{20}$. Also, obvious nasal symptoms or external physical signs which may alert those unfamiliar with frontal sinusitis as to the probable diagnosis are absent.

The fact that $82 \%{ }_{18}$ of the patients who develop a rhinosinugenic abscess were initially seen in a non ENT department where neither the underlying frontal sinusitis nor the developing intracranial complication had been suspected indicate that the diagnosis of frontal sinusitis in patients complaining of frontal headache is rarely considered outside of an ENT department. This may explain the persistence in incidence of mortality and morbidity in this condition several years after the introduction of antibiotics and high technology neuroimaging facilities. In a patient with acute frontal headache, with or without periorbital oedema, plain radiograph of the frontal sinus should be done to exclude frontal sinus infection as a cause. As there is a significant risk of intracranial complication developing in patient with frontal sinusitis ${ }_{20}$ with the advent of CT scan however, patients will benefit more from its superior imaging capacity.

All the patients had epidural abscess, subdural abscess in three, and intracerebral collections occurred within the frontal lobe twice, and the temporal and parietal lobes once. The multilocular abscesses was found in two patients and this is similar to the finding by $\mathrm{C}$ Arseni et $\mathrm{al}_{22}$ in which multilocular forms make up $45.65 \%$ of the total number of rhinosinugenic cerebral abscess.

The frontal, ethmoidal and the maxillary sinuses were involved in all the patients while the sphenoidal sinus was involved in two patients.

Microbiological studies showed a mixed growth of gram positive cocci, gram negative bacilli in one patient, peptostreptococci in one, unspecified gram positive cocci in one with no growth of organism in the fourth patient. Boles (1980) also found the streptococcus to be the dominant causal organism in intracranial abscesses resulting from frontal sinusitis. Strept Milleri is however was the most common causative organism found by J.E Fenton, D.A Smyth, L.G Viani and M.A Walsh ${ }_{23}$. Blood culture was done in all the patients and it gave no yield. This is similar to what was found by J R Moloney, N J Badham, and A McRae ${ }_{24}$. This is probably due to the use of various antibiotics before presentation. Also the nonavailability of microbiological facilities for carrying out anaerobic studies was a major limitation although all the patients were placed empiricaly on parenteral antianaerobes in addition to other antibiotics based on sensitivity. They all had other supportive management including blood transfusion, nutritional support and intensive care facilities.

Radical surgery was used for both the intracranial and the paranasal sinus collections. Three patients had craniotomy for the drainage of the intracranial abscess while one of the patients had burrhole. Paranasal sinus disease was also treated with frontoethmoidectomy with frontal sinus obliteration with fat, frontoethmoidosph-

enoidotomy, and antral washout. Three of the patients described here made good progress following radical surgeries of the brain and the paranasal sinuses with intravenous antibiotics, although were left with morbidities including hemiparesis, speech defect the follow-up and management of which posed a lot of challenges including irregular clinic attendance and did not recover completely before being lost to follow-up. Morbidity in three of these four young boys should further underscore the importance of early diagnosis and treatment of this primary source of intracranial and other associated complications. In agreement with Nash (1956) ${ }_{25}$ it is our own opinion that considerable importance should be given to radiology and especially nowadays, to computerized axial tomography and magnetic resonance imaging which are capable of casting light on the diagnosis in doubtful cases.

Although mortality rate between $28 \%_{13}$ and $47 \%_{17}$ has been documented in previous studies, only one out four patients in this report died, it is however difficult to make a valid comparison due to the relatively fewer number of patients in this review and a more elaborate study needs to be done on this in the future. 
Small et al ${ }_{3}$ however reported a drop in their mortality rates from $27.5 \%$ to $6.5 \%$ following the introduction of their CT scanner in 1975, the reduction was not shown to be statistically significant, there is still a paucity of literature on this in this environment.

Mortality is directly related to the extent of infection of the contiguous structures like the orbit, periapical region, the level of consciousness at presentation, being as high as $83 \%$ in patient with deep coma ${ }_{26}$. This finding is similar to what we found in which the only mortality had multiple sites of abscesses including the orbit, left upper molar periapical region, left parotid gland, apart from the paranasal sinuses and the multiple intracranial sites. This patient also had financial limitations which impaired a regular administration of antibiotics and other drugs and also for investigations.

Insidious symptomatology may explain why patients with this problem do not give their problem the attention due to it. In addition it has been establish that people in this environment have a poor health seeking habit, and the involvement of males alone may also be due to the carefree attitude of this young males compared to their female counterparts. In this series three of the patients were seen in the hospital after developing periorbital swelling, seizure and hemiparesis.

Mortality rates from sinugenic intracranial abscesses has remained significant despite advances in medicine, i.e. antibiotics and CT scan for early and accurate diagnosis and it ranges between $8 \%_{27}$ and $16 \%_{28}$

\section{CONCLUSIONS}

Sinugenic intracranial abscess is still common in our environment. Improper management of conditions commonly referred to as common cold by the uninformed public and quacks are among other things the aetiology. Several more patients are likely dying in the community without getting to the hospital. All the survivors of this condition came down with morbidities the management of which are on their own expensive to manage and difficult to cope with by the patient due to the need for frequent hospital visits which patients do not comply with. This can only be tackled through education.

The unspecific nature of the presentation at the early stage coupled with improper handling of nasal conditions by the non ENT specialists may contribute to advanced mode of presentation. So primary physicians should be made to undergo regular update courses in ENT and the rotation of other residents doctors through ENT should be structured to expose them better.

Clinical presentation of subdural empyema can be relatively unspecific, requiring a high degree of suspicion. Facing a young male adolescent with fever of unknown origin associated with any neurological abnormality and previous history of sinusitis, neuroradiological investigation should be asked. Early diagnosis and treatment are the mainstays of successful outcome. This primarily involves the Otorhinolaryngologist and the Neurosurgeon.

CT scan facility should not only be made available but also affordable to the common man in our environment as in other developed nations. This can be done by making the machine available at all tertiary health centers at affordable costs with the maintenance facilities also provided so as to reduce the rate of frequent prolong breakdowns. Clinicians ability to suspect the diagnosis is of utmost importance.

\section{CORRESPONDENCE TO}

Dr. A.O. ADENIJI Senior Registrar ENT Unit, Department of Surgery Obafemi Awolowo Univesity Teaching Hospitals Complex, P.M.B 5538, Ile-Ife. Nigeria. E-mail:

gbolaad@yahoo.com

\section{References}

1. D.A Nunez, Presentation of rhinosinugenic intracranial abscess, Rhinology, 29 (2) (1991) 99 - 103.

2. A.O.A Ogunleye, O.G.B Nwaorgu, A.O Lasisi,

Complications of sinusitis in Ibadan, Nigeria, WAJM 20(2) (2001) 98-101.

3. Small M, Dale B.A, Intracranial suppuration 1968-1982- a 15 year

review ,Clin Otolaryngol Allied Sci 1984 Dec;9(6):315-21

4. Kunanov N.I, Orbital and Intracranial complications of rhinosinusitis, vestn otorhinolarynagol. (4) (2001) 46 - 7.

5. Evans Kathryn L, Diagnosis and Management of sinusitis British

Medical Journal, (309) (1994) 145 - 1422.

6 . Andrew Blitzer, Peter W Carond, Intracranial complication of disease of the paranasal sinuses, surgery of the paranasal sinuses Chapter 32 (1991) 471.

7. Fairbanks D.N.F et al: Intracranial complications of sinusitis. In English E (ed) Otolaryngology. New York, Harper and Row, 1983 p1.

8. Carmel P.W: Focal infections of the neurons systemic

Rudolph Am (ed): paediatrics 17th ed. Norwalk, CT

Appletion - century - crofts 1982 p61.

9. John Groves and Roger F.Gray. Complications of suppurative sinusitis.In a synopsis of

Otolaryngology.Wright,Bristol 1985; pp. 211-215

10. Moshes H.P, Judd D.K: An analysis of seven cases of osteomyelitis of frontal bone complicating frontal sinusitis laryngoscope (43): (1933) 153.

11. Yoger R: Suppurative intracranial complications of upper respiratory tract infections.pediatr infect Dis J. (6) (1987) 324.

12. Maniglia AJ et al: Intracranial infections secondary to 
nasal sinus and orbital infections in adults and children Arch otolaryngol Head and Neck Surg. (115) (1989) 1424.

13. Bradlay P.J, Shaw M.D.M Three decades of brain abscess in Merseyside J R Col Surg Edinb 28 (1983) 223-8 14. Devgan B.K, Devgan M, Cross C.W, Blastomycosis of fronto-ethmoid complex, South-med J 1978, 71 (2) : 191-194.

15. Sable N.S, Hangerer A, Powell K.R. Acute frontal sinusitis with intracranial complications. Paediatric infectious disease 1984, (3) : 58-61

16. Balm A.J, Tiwari R.M, de-Rijeke T.B, Osteomyelitis of the Head and Neck. Journal of Laryngol Otol 1985 99(10) :1059-1065

17. Bradlay P.J, Maning K.P, Shaw M.D.M, Brain abscess secondary to otitis media J laryngol Otol 98 (1984) 1185-91 18. S Chalstrey, A.G Pfleiderer, D.A Moffat, Persisting incidence and mortality of sinugenic cerebral abscess: a continuing reflection of late linical diagnosis, Journal of the Royal Society of Medicine, (84) (1991) 193-195

19. Amadasun J.E.O, Managing sinugenic complications in Nigerian setting, West African Newsletter of

Otorhinolaryngology, Head and Neck surgery. (1997): pg 3-9.

20. Davies P.T.G, Clifford Rose F, Headache-including migraine. Hospital update (13) (1987) 763-778
21. Stuart E.A, O'brien F.H, McNally W.J. Some observations on brain abscess, Arch otolaryngol (61) (1955) 212-217

22. C Arseni and A.V Ciurea, Rhinogenic cerebral abscesses, Zentralbl Neurochir, 43(2) (1982) 129-42 23. J.E Fenton, D.A Smyth, L.G Viani and M.A Walsh, Sinugenic brain abscess, Am J Rhinol, 13 (4) (1999) 299-302

24. J.R Moloney, N.J Badham, and A McRae, The acute orbit. Preseptal (periorbital) cellulites, Subperiosteal abscess and orbital cellulites due to sinusitis J laryngol Otol Suppl, (12) (1987) $1-8$

25. Nash C.S Osteomyelitis of the frontal bone,Archives of otolaryngology (64) (1956) 108-117.

26. Algeria C, lipechitz R, Zwonnikoff G, Intracranial suppuration:a review of 79 cases seen at Baragwaneth Hospital over 3 years, S Afr J Surg (20) (1982) 2-35

27. Quraishi H, Zevallos J.P, Subdural empyema as a complication of

28. Int J Pediatr Otorhinolaryngol.2006 sep;70(9): 1581-6. Epub 2006 Jun 14.

29. Singh B, Van Dellen J, Ramiettan S, Maharai T.J Sinugenic Intracranial Complications, J Laryngol Otol. 1995 Oct;109(10):945-50 


\section{Author Information}

A.O. Adeniji, MBBS

Senior Registrar, ENT Unit

Y.B. Amusa, B.Sc MB,CHB, FMCORL

Consultant ENT Surgeon

O.V. Akinpelu, MB,CHB,FWACS,FMCORL

Consultant ENT Surgeon

\section{A.A. Adeolu, MB,CHB, FWACS}

Consultant Neurosurgeon

E.O. Komolafe, MB,BS, FWACS

Consultant Neurosurgeon

O.A. Onipede, FMCPATH

Consultant Microbiologist 